Natural Hazards and Earth System Sciences, 6, 49-54, 2006

SRef-ID: 1684-9981/nhess/2006-6-49

European Geosciences Union

(c) 2006 Author(s). This work is licensed

under a Creative Commons License.

\title{
Vulnerability of Russian regions to natural risk: experience of quantitative assessment
}

\author{
E. Petrova \\ Faculty of Geography, Research Laboratory of Snow Avalanches and Debris-flow, Lomonosov Moscow State University, \\ 119992 Moscow, Russia
}

Received: 15 July 2005 - Revised: 30 September 2005 - Accepted: 24 October 2005 - Published: 13 January 2006

\begin{abstract}
One of the important tracks leading to natural risk prevention, disaster mitigation or the reduction of losses due to natural hazards is the vulnerability assessment of an "at-risk" region. The majority of researchers propose to assess vulnerability according to an expert evaluation of several qualitative characteristics, scoring each of them usually using three ratings: low, average, and high. Unlike these investigations, we attempted a quantitative vulnerability assessment using multidimensional statistical methods. Cluster analysis for all 89 Russian regions revealed five different types of region, which are characterized with a single (rarely two) prevailing factor causing increase of vulnerability. These factors are: the sensitivity of the technosphere to unfavorable influences; a "human factor"; a high volume of stored toxic waste that increases possibility of NDs with serious consequences; the low per capita GRP, which determine reduced prevention and protection costs; the heightened liability of regions to natural disasters that can be complicated due to unfavorable social processes. The proposed methods permitted us to find differences in prevailing risk factor (vulnerability factor) for the region types that helps to show in which direction risk management should focus on.
\end{abstract}

\section{Introduction}

Research dealing with natural hazards, natural risk, and natural disasters mostly examines either geophysical characteristics of natural hazards, or human pre- or post-disaster activities. More recent studies consider that natural disasters (ND) are also socially constructed. Weichselgartner (2001) emphasised that disasters are seen as social phenomena whereas the overall damage due to natural hazards is the result both of natural events that act as "triggers", and a series of societal factors. Some other researchers also consider ND to be social

Correspondence to: E. Petrova

(epgeo@mail.ru) and economic phenomena rather than geophysical and technical ones (Global Change, 1991; Miagkov, 2001). We also share this point of view and propose an integrated approach to natural risk.

We regard a ND as a disturbance of the current activity of a populated region due to abrupt natural impacts (a catastrophe or accident) resulting in social, economic, and (or) ecological damage, which requires special management efforts for its elimination. Thus a ND is the result of an interaction between a hazardous natural phenomenon and society. Therefore, we would not call for example an earthquake, snow avalanche or other natural hazard event in a non-settled region of Siberia a disaster. Russian statistics regard disasters as phenomena causing four or more fatalities, and (or) injuring 10-15 people, and (or) damaging more than 500000 rubles (US\$ 17000). The same criteria were used for our study.

Natural risk investigations focus on risk prevention, disaster mitigation or the reduction of losses due to natural hazards. One of the important tracks leading to these goals is the vulnerability assessment of an "at-risk" region, and researchers can approach this task in different ways, using various indices to define vulnerability. There is no common conceptualisation of vulnerability and there are no common methods of vulnerability assessment (Cutter, 1996; Weichselgartner, 2001).

Firstly we should define our concept of vulnerability. By vulnerability we mean the sensitivity of a region to the influence of unfavourable and dangerous natural events or phenomena, and the capability of this region to cope with such influences. The vulnerability of a region is determined by both the range of damage and loss from dangerous events, and the scale of emergency due to a ND. It is determined not only by the physical parameters of natural hazards in themselves, but also by economic and social conditions (Petrova, 2004).

The majority of researchers propose to assess vulnerability according to an expert evaluation of several qualitative 
Table 1. Schema for typological differentiation of Russian regions (Gladkewitch, Kruzhalin, and Mazurov).

\begin{tabular}{lccc}
\hline $\begin{array}{l}\text { Potential of natural } \\
\text { disaster occurrences }\end{array}$ & $\begin{array}{c}\text { pilot } \\
\text { developing }\end{array}$ & $\begin{array}{c}\text { Type of region } \\
\text { transition type }\end{array}$ & $\begin{array}{c}\text { old } \\
\text { developing }\end{array}$ \\
\hline Low & I & II & III \\
Average & IV & V & VI \\
High & VII & VIII & IX \\
\hline
\end{tabular}

\section{Vulnerability}
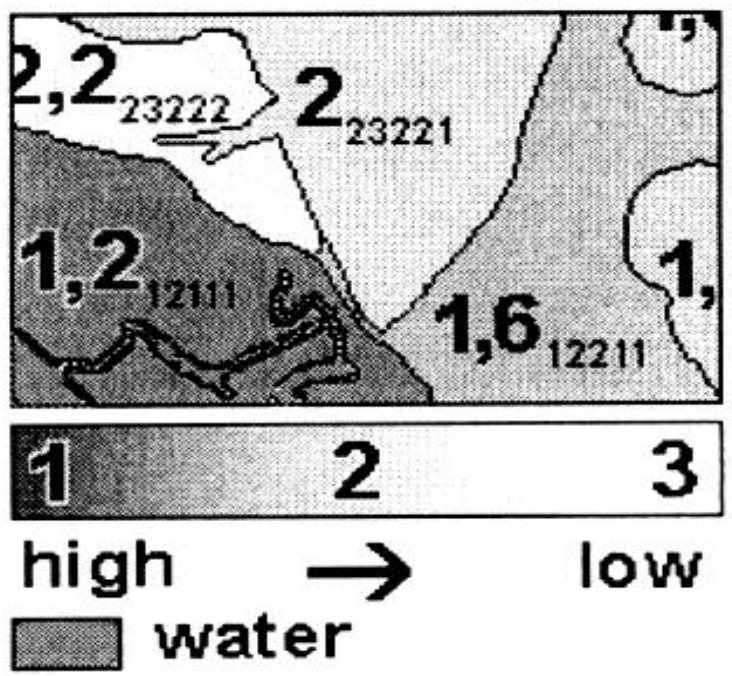

\section{1 - 3 - Degree of vulnerability.}

Fig. 1. Example of vulnerability map (Weichselgartner, Bertens).

characteristics. They mainly take a set of various qualitative factors which determine potential risk and score each of them usually using three ratings: low, average, and high. Previously we proposed a typification of the regions in Russia according to their liability and sensitivity to unfavourable natural phenomena. The following factors are considered in the typification of regions: their economic type, age, size, economic and territorial structure, population density, socialpolitical condition, ecological situation, uniqueness of a region or the positioning on its territory of particular objects, i.e. residence regions of indigenous and small nations, regions with unique natural formations, etc. (Petrova, 1999).

We can see another example of this in Table 1. This is a schematic diagram of the typological differentiation of regions, proposed by Gladkevitch, Kruzhalin, and Mazurov (2000). They take into account the land-use type such as pilot developing, old developing, and transition type, as well as the potential of ND occurrences (low, average, and high). As a result, they have divided regions into nine types, but

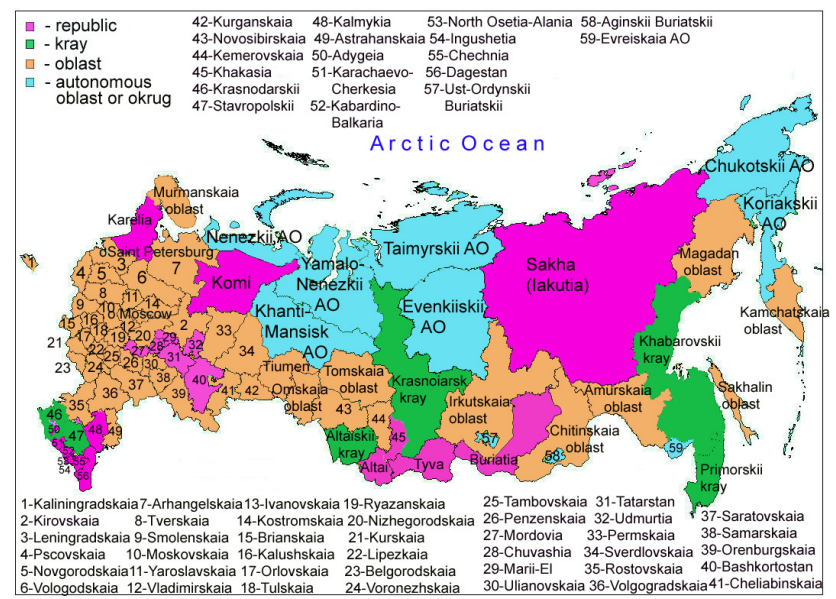

Fig. 2. Administrative division of the Russian Federation.

their classification of regions to one or other type is more subjective.

An interesting approach was proposed by Weichselgartner and Bertens (2000) for flood hazards. They considered five factors which determine potential damage in any given area: 1) the hazard (the physical process itself); 2) exposure (all individuals, infrastructure, etc. which are exposed to the hazard); 3) preparedness (all precautionary activities and measures which enable a rapid and effective response to hazardous events); 4) prevention (all the activities and measures taken in advance of a hazardous event designed to reduce hazards and their effects and to provide permanent protection from their impact); and 5) response (all activities and measures taken immediately prior to and following a hazardous event to reduce the impact and to recover and reconstruct an area affected by a hazardous event). Weichselgartner and Bertens assessed these factors with indicators that were expressed in binary form. The resulting map of vulnerability shows an average indicator of all considered factors in each area (Fig. 1). The "average class value" obtained is based on the assumption that all factors are equally important. The corresponding values of the considered factors are shown as subindices.

Unlike the above mentioned researches, we attempted a quantitative vulnerability assessment. We have typified the regions of Russia by their vulnerability to natural risk using multidimensional statistical methods.

\section{Research region}

The Russian Federation (RF) was the region of research (Fig. 2). The RF consists of 89 main administrative units (federal regions), including republics (such as Karelia, Komi, and the Republic of Dagestan), territories or kray's (such as Krasnodarskii Kray, Krasnoiarskii Kray, and Primorskii Kray), oblast's (such as Moskovskaia Oblast' and Leningradskaia Oblast'), and autonomous areas (oblast's or okrugs such as Khanti-Mansisk Autonomous Okrug and Evenkiiskii 
Autonomous Okrug). These units correspond to states in the USA or federal lands in Germany. Incidentally, the largest Russian cities, Moscow and Saint Petersburg are considered as separate federal regions. The level of the main administrative units (or federal regions) was taken for the research because comparable statistical data for these administrative units are available for assessment. Official statistical data in Russia are published for these 89 units of the highest administrative level.

More than 4100 ND events were recorded in Russia between 1990 and 2004, giving an annual average number of 282 ND (in the 1980s, the annual average number of NDs ranged from 110 to $130 \mathrm{ND})$. In fact, $186 \mathrm{ND}$ were registered in 1990, while there were 465 ND in 1998 (the maximum) and $231 \mathrm{ND}$ in 2004 (Fig. 3). On average, each year NDs cause the death of 139 people and affect 46, 287 people in Russia (Emergency Ministry of Russia, 1994-2005).

More than 30 types of disaster-causing natural hazards can be observed in Russia. The most destructive of them are floods, hurricanes, storm wind, earthquakes, erosion, landslides, debris flow, soil subsidence, snow avalanches, heavy frost, and frozen ground.

\section{Methods and parameters}

We made a cluster analysis of all the 89 federal regions. Cluster analysis takes disparate objects (in this case, the 89 federal regions) and groups them according to shared, common characteristics (Devis, 1977). We used a variant of cluster analysis based on agglomerative hierarchical procedures, which unite the units with the minimal distance in a multidimensional space of features at every step. The number of steps and the final number of groupings were not determined a priori but resulted automatically from the computational analysis. The applied procedure permits us to find the parameters which characterised each cluster, without specifying a priori the relative weighting of each parameter.

We have selected statistical indicators which could better indicate the social and economic conditions in the Russian regions, which affect their vulnerability to NDs. The period between 1994 and 2002 was taken for the assessment.

We have taken the following parameters:

1. The per capita production of the Gross Regional Product $(G R P)$ is the most informative economic parameter which describes differences in the regional social and economic conditions, which in turn determine the availability of material resources for the reduction of vulnerability.

2. Wear and tear of industrial equipment as well as social and industrial infrastructure, including industrial plants, pipelines, power, water, and heat supply systems, lines of communications, travel assets, dams, and other technical objects (capital consumption) was taken for appropriate calculation as a parameter which increases vulnerability. According to official data from the Russian

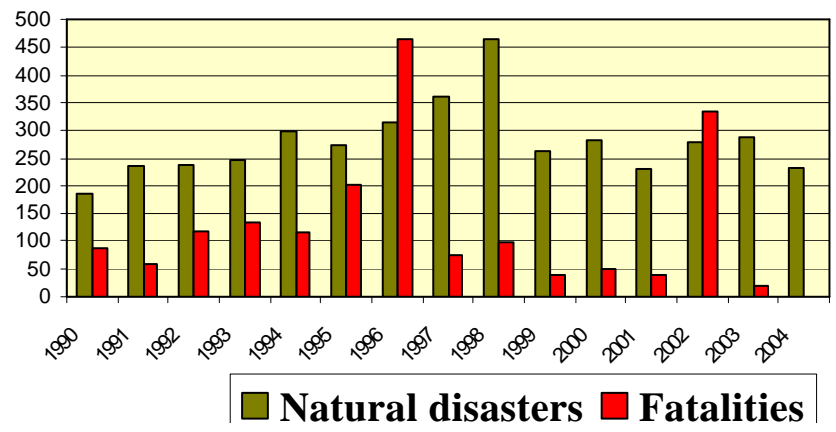

Fig. 3. Number of natural disasters and fatalities in Russia.

Ministry of Emergencies a high level of worn out technical objects is one of the fundamental reasons for all disasters in Russia.

3. The volume of stored toxic waste was measured as a parameter which increases vulnerability; the greater the volume of stored toxic wastes in a region, the greater the severity of disasters when natural hazards cause destruction of toxic waste depots.

4. The level of criminality was taken as an indicator of social troubles, which also increase vulnerability. An index, traditionally used in sociology, was used to gauge social troubles as such a factor.

Of course, increasing negative social, ecological, and economic conditions do not directly influence the occurrence of NDs. Nevertheless, these negative events reduce awareness of any emergencies, thus increasing their severity. As a result the possibility of natural disasters and human-caused accidents increases while current protection costs aimed at the reliability of infrastructure and industrial units are reduced. Hence, all these factors increase the natural and human-caused risk, and vulnerability of a region.

5. We have also taken an annual average number of NDs per 1000 people as an index of the occurrence of regional natural disasters.

Official State Reports of the Russian Ministry of Emergencies (Russian Ministry of Emergencies, 1994-2005) and statistical data from the State Statistical Committee of Russia were used as input data (State Statistical Committee of Russia, 2001).

\section{Results}

Using all these parameters, cluster analysis for all 89 Russian federal regions revealed five different types of region. The number of types resulted automatically from the computational analysis. The applied procedure also permitted us to find the parameters which characterised each type. It is interesting that every type of region has an unusually high value 

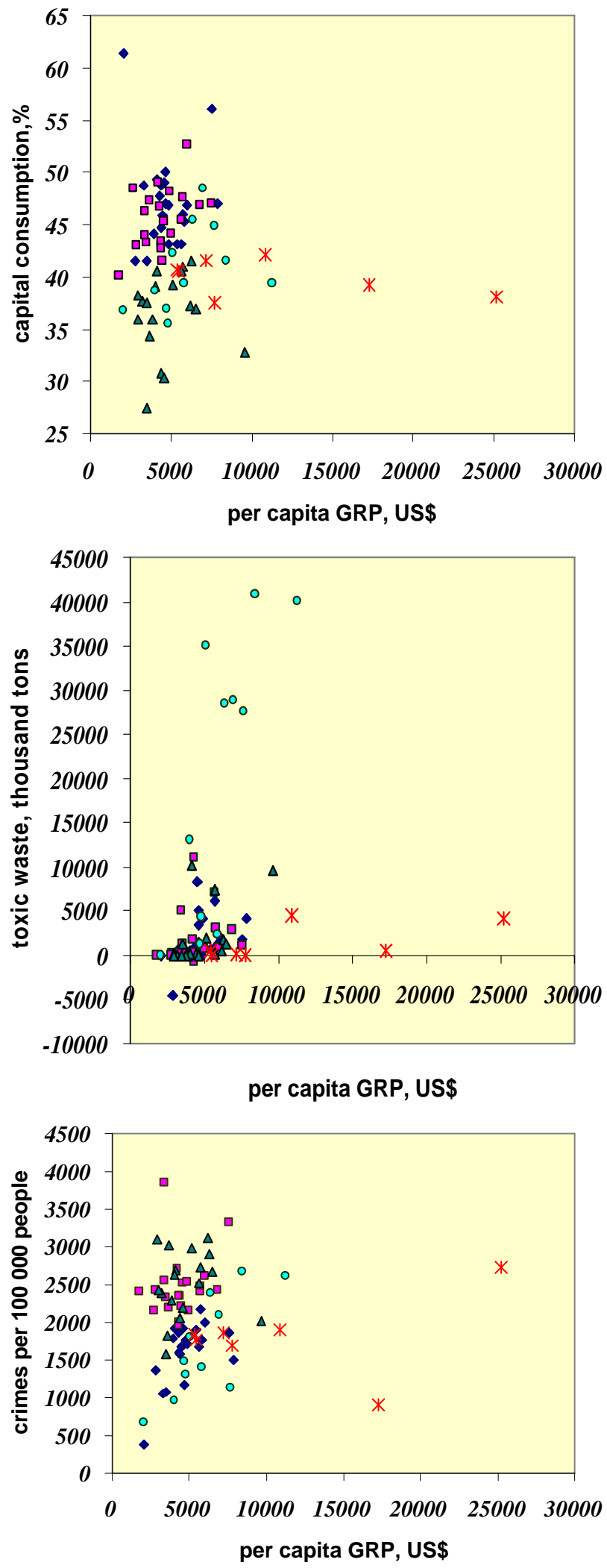

- type 1 type $2 \Delta$ type $3 \circ$ type $4 *$ type 5

Fig. 4. The main characteristics for types of regions. of a single (rarely two) parameter. These very parameters can indicate a prevailing factor of vulnerability for each type. The differences between these types are distinctly shown on the graphs (Figs. 4a, b, and c). So, in Fig. 4a we can see that the first and the second types (marked with blue rhombi and pink squares, correspondingly) have higher levels of capital consumption. The regions of the second and the third types (pink squares and green triangles) have higher levels of criminality (Fig. 4c). The regions of the fourth type (turquoise ovals) have higher volumes of toxic waste (Fig. 4b). And the regions of the fifth type (red crosses) have higher per capita GRP, a middle level of capital consumption as well as relatively low volumes of accumulated toxic waste and levels of criminality (Figs. 4a, b, and c). The given values are based on statistical data for the 2001. A negative value in Fig. 4b stands for higher level of waste utilization in comparison with level of waste accumulation in a region.

Thus, the analysis permitted us to find a prevailing risk factor (factor of vulnerability) for each type of region.

1. The first type of region is generally characterized by an unusually high level of capital consumption (Fig. 4a). Essentially, these are the old developed regions of the central and south part of the European Russia. Here, the sensitivity of the technosphere to unfavorable influences is the main prevailing risk factor (factor of vulnerability).

2. The second type is characterized by both high levels of capital consumption and criminality (Figs. 4a and c). These regions are largely found in the north and centre of European Russia, as well as in the mid-Urals, and South-West and Eastern Siberia (Chitinskaia Oblast', Tyva Republic). Since the dynamics of NDs in these regions are governed by a heightened vulnerability of the technosphere, besides natural reasons, it can be said that these influences are "human factor".

3. The third type is marked by the highest level of criminality (Fig. 4c). Regions of this type have also the highest quantity of ND per 1000 people. These regions are of the North (Karelia and Komi Republics), NorthWest (Pskovskaia and Leningradskaia Oblast's), VolgoViatskii (Marii-El and Chuvashia Republics), and also the Altai, Khakasia, Buriatia Republiks, Irkutskaia Oblast', and virtually all of the Far East (except Iakutia). In comparison to the national average, the heightened liability of regions to natural disasters can be complicated here due to unfavorable social processes.

4. The fourth type is characterized by a high volume of toxic waste (Fig. 4b). The following regions of this type include: Vologodskaia, Moskovskaia, Belgorodskaia, Ulianovskaia, Orenburgskaia, Cheliabinskaia, Kemerovskaia Oblast's, the Republics of Bashkortostan and Kabardino-Balkaria, Krasnoiarskii Kray. In this group, the unfavorable dynamics of the remaining analyzed factors create a threat of NDs with serious consequences. 


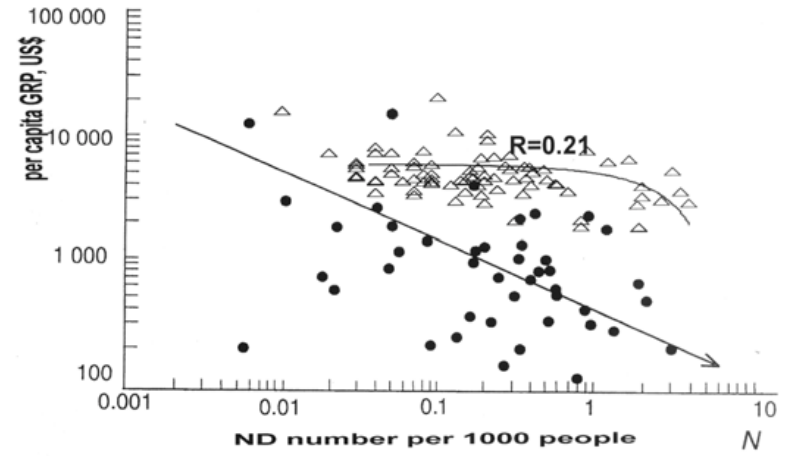

- - The countries of the world

$\Delta$ - The federal regions of Russia.

Fig. 5. Interrelation between Gross Regional Product and the number of natural disasters in the world and in Russian federal regions.

5. Seven regions of the fifth type are the most successful from all points of view. They have both high per capita GRP and relatively low values of all parameters increasing vulnerability. These are Moscow, Murmanskaia, Nizhegorodskaia, Tiumenskaia Oblast's, the Kalmyk Republic, Tatarstan and Sakha (Iakutia).

The regions of the types one to three simultaneously have relatively low values of per capita GRP, which reduce the availability of material resources for prevention and protection activities and measures. This is an additional factor increasing vulnerability. Earlier we found an inverse relationship between the per capita GRP and the annual average number of ND per 1000 people (Petrova, 2004). In principle, this correlation is similar to that between per capita Gross Domestic Product and the number of NDs, which was found during the International Decade for ND Reduction on the international level (IDNDR, 1994). In Fig. 5 we can see the comparison of these international results (marked with black points) with our results for all the 89 Russian federal regions (marked with triangles). However, the coefficient of correlation for the totality of federal regions is too low $(-0.21)$, which is why we tried elucidate a more precise definition of this correlation. We have shown that this relationship is seen more distinctly in those regions, where either the number of NDs or per capita GRP is unusually high (Fig. 6). In the first case (marked with rose squares) the coefficient of correlation is -0.61 . The relatively small increase of the per capita GRP corresponds to a sharp reduction of the number of ND in this group. In the second case (marked with green triangles) the coefficient of correlation is -0.69 . The regions in this group simultaneously have unusually high values of per capita GRP and unusually low ND numbers. One can assume that this relationship is due to a result of reducing vulnerability after the per capita GRP has exceeded a certain level.

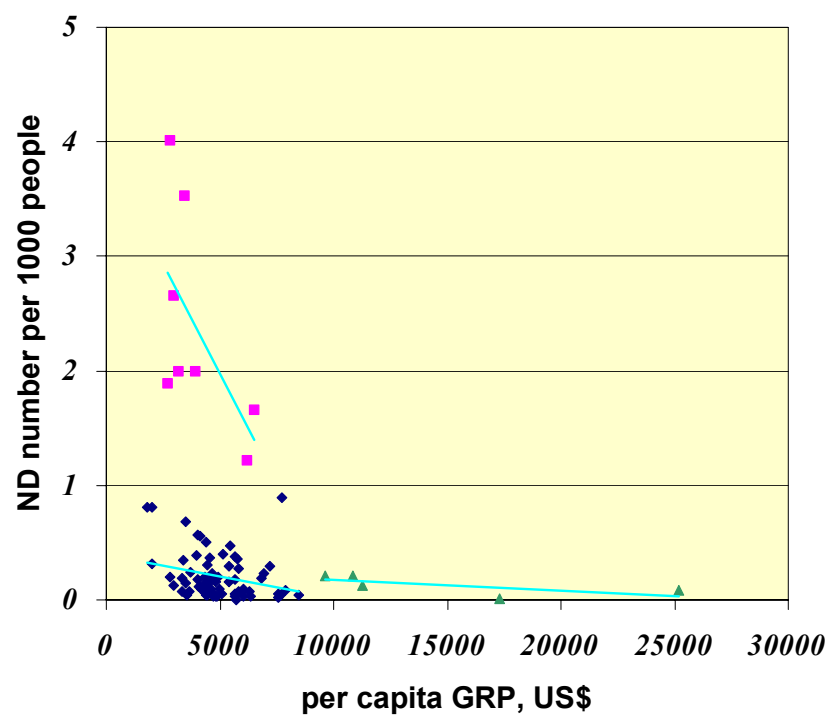

- The background regions

- The regions with unusualy high ND number

$\Delta$ The regions with unusualy high per capita GRP

Fig. 6. Interrelation between Gross Regional Product and the number of natural disasters in Russia.

\section{Discussion}

The applied methods permitted us to find differences in prevailing risk factor for the region types (vulnerability factors), without specifying a priori the relative weighting of each parameter. These factors are: the sensitivity of the technosphere to unfavorable influences; a "human factor"; a high volume of stored toxic waste that increases possibility of NDs with serious consequences; the low per capita GRP, which determine reduced prevention and protection costs; the heightened liability of regions to natural disasters that can be complicated due to unfavorable social processes.

That is the main difference between the proposed approach and the approaches based on a calculation of an average indicator of vulnerability and on the evaluation of qualitative characteristics. Using the proposed methods, it is possible to draw the conclusion from different factors, influencing the rise or fall of vulnerability. This approach helps to show in which direction risk management should focus on.

The shortage of proposed methods lies in the fact that it allows the inclusion in the estimate only those parameters, which give way to qualitative measuring. Together with this, it allows for more reliable results, in comparison with expert opinion using as its base subjective assumptions.

Acknowledgements. The author would like to express her thanks to Y. Mironov and T. Vashchalova for important remarks, which were accepted. Special thanks go also to G. Symons for help in translating this paper into English.

Edited by: T. Glade

Reviewed by: W. Schaal and another referee 


\section{References}

Cutter, S. L.: Vulnerability to environmental hazards, Progress in Human Geography, 20, 529-539, 1996.

Devis, D.: Statistics and Analysis of Geological Data, (in Russian), Moscow, 1977.

Emergency Ministry of Russia: State reports of Russian Ministry of Emergencies about Protecting Population and Territory of Russian Federation against Natural and Technological Disaster in 1993-2004, (in Russian), Moscow, 1994-2005.

Gladkevitch, G. I., Kruzhalin, V. I., and Mazurov, Y. L.: Typological Differentiation of the territory taking into Account the Risk Consequences of Natural Calamity, (in Russian), Letters of the Russian Academy of Sciences, Geographical series, 6, 57-65, 2000.

Global Change: Geographical Approaches, Nucson, Univ. of Arizona Press, 1991.

IDNDR, Promotion Office: Natural Disasters in the World, Statistical Trend on Natural Disasters, Japan, National Land Agency, 1994.
Miagkov, S. M.: Social Ecology, Ethnic, and cultural foundations for sustainable development, (in Russian), Moscow, 2001.

Petrova, E. G.: Typification of the Russian regions according to their liability and sensitivity to unfavourable natural influences, (in Russian), N. M. Przhevalskij and modern Regional Geography, Smolensk, 87-90, 1999.

Petrova, E.: Social and economic factors of the natural risk increasing: estimation of the Russian Regions, Nat. Hazards Earth Syst. Sci., 4, 243-248, 2004,

SRef-ID: 1684-9981/nhess/2004-4-243.

State Statistical Committee of Russia: Regions of Russia 2000, Statistical Yearbook, (in Russian), Moscow, 2001.

Weichselgartner, J.: Disaster mitigation: the concept of vulnerability revisited, Disaster Prevention and Management, 10, 85-94, 2001.

Weichselgartner, J. and Bertens, J.: Natural disasters: acts of God, nature or society? - On the social relation to natural hazards, Risk Analysis II, edited by: Brebbia, C. A., WIT Press, Southampton, 3-12, 2000. 